\title{
Applications of Internal Friction to Studies of Iron and Steels
}

\author{
By Koichi Aoki*, Syozo Sekino* and Toshiyuki Fujishima*
}

\section{Introduction}

The ability of a vibrating solid, which is completely isolated from its surroundings, to convert its mechanical energy of vibration into heat is called "internal friction" (IF). In metals, the following physical phenomena may be investigated by means of $\mathrm{IF}^{1) \sim 4)}$ :

(a) Diffusion of interstitial atoms;

(b) Movement of dislocations;

(c) Diffusion or migration of metal atoms or vacancies;

(d) Electrical or magnetic phenomena.

In the field of iron and steel research, the study of phenomenon (a), especially the application of measurement of the Snoek peak, has brought the most fruitful results. ${ }^{5)}$ 7)

The Snoek peak is caused by the following mechanism: when the interstitial atoms jump between sites that are the nearest neighbours under an alternating stress, the largest energy loss occurs at a definite temperature, at which the energy of vibration is converted into heat for the most part. When pure iron is tested at the frequency of one cycle per second $(\mathrm{c} / \mathrm{s})$, the internal friction peaks by $\mathrm{N}$ and $\mathrm{C}$ atoms appear at $23^{\circ} \mathrm{C}$ and $39^{\circ} \mathrm{C}$, respectively. $\left.{ }^{5), 8)} \sim 10\right)$

As for the phenomenon (b), there is IF called background which is the residue after subtracting the Snoek peak portion from the curve showing variation of internal friction with temperature. Its characteristic is the high amplitude dependence. This is explained by unpinning of dislocations. ${ }^{11), 12)}$

The Köster effect is related to the above IF due to dislocations. ${ }^{13)}$ After deformation or quenching, IF becomes very high but decreases very rapidly with time, and is explained as due to pinning down of the dislocations by vacancies or interstitial atoms diffusing there.

Another interesting phenomenon is the Köster peak. ${ }^{14), 15)}$ When iron is deformed or quenched, an IF peak appears between $180^{\circ} \sim 250^{\circ} \mathrm{C}$ at $1 \mathrm{c} / \mathrm{s}$, the mechanism of which has not been clarified as yet, although several investigations have proposed the mechanism.

Besides these IF phenomena, there are also interesting ploblems concerning IF at high temperatures which are now being studied, such as the peak caused by the viscosity of the grain boundary, ${ }^{16)}$ and the change of IF by recrystallization. These problems are left for future investigations.

\section{Snoek Peak and Its Applications}

1. Snoek Peak Caused by $\mathcal{N}$ and $C$ in Iron

The theoretical explanations of this effect were pre- sented by Snoek ${ }^{5)}{ }^{6)}$ and Polder. ${ }^{7)}$ When $\mathrm{N}$ and $\mathrm{C}$ atoms in iron resume the equilibrium distribution as decided by the applied stress, it takes almost as long as the time required for stress relaxation. If the temperature is low, and thus, the relaxation time is longer than the period of one cycle of stress, $\mathrm{N}$ and $\mathrm{C}$ atoms do not change their positions with the applied alternating stress. Then, the total strain is elastic and in phase with the stress, such that the energy of vibration is not dissipated. On the other hand, when the temperature is so high that the $\mathrm{N}$ and $\mathrm{C}$ atoms may change their positions in a shorter time than the relaxation time, non-elastic strain is zero, since the solute atoms can instantaneously restore the equilibrium position under the stress, and the stress and the strain are in phase. Between these two extreme cases, there is a non-elastic strain with a retarded phase which is not completely zero, such that the phase of total strain is retarded a little, causing energy loss. The maximum loss occurs when the mean jump time of interstitial atoms becomes about $1 / 4$ of the period of one cycle. Therefore, when IF is measured by changing the frequency at constant temperature, a peak is found at a definite frequency. But from experimental difficulties, the temperature is usually changed at constant frequency, using the fact that the mean jump time changes exponentially with the temperature.

According to Snoek's theory, the height of the peak $(1 / Q)_{\max .}$ is

$$
\begin{aligned}
& (1 / Q)_{\max }=k^{\prime} \quad c / T=k c \\
\text { where } k^{\prime}= & \text { constant, } \\
k= & \text { constant at } 1 \mathrm{c} / \mathrm{s}, \\
c= & \text { concentration of interstitial atoms, } \\
T= & \text { absolute temperature at the peak. }
\end{aligned}
$$

If $k$ is found experimentally, the quantities of interstitially dissolved $\mathrm{N}$ or $\mathrm{C}$ may be calculated.

There is the following relationship between the frequency $f$ and the peak temperature $T$ :

$$
2 \pi f \cdot \frac{a^{2}}{36 D_{0}} \cdot \exp \left(\frac{H}{R T}\right)=1
$$

where $D_{0}=$ preexponential factor in diffusion const., $H=$ activation energy in diffusion, $a=$ atomic distance of iron, $f=$ frequency of stress.

Inserting the known constants into equation (2), the following equations for $\mathrm{N}$ and $\mathrm{C}$ are obtained:

$$
\begin{aligned}
& \mathrm{N}: 13.35-\log f=\frac{3960}{T} \\
& \mathrm{C}: 14.35-\log f=\frac{4450}{T}
\end{aligned}
$$

* Yawata Iron \& Steel Co., Ltd. 


\section{Relation between the Peak Height and Interstitial Atoms}

In order to get $k$, the amount of $\mathrm{N}$ and $\mathrm{C}$ atoms that are precipitated and/or trapped by the grain boundaries, vacancies and dislocations must be known. Actually, if one performs the experiment under deliberate conditions, and compares the peak heights with the chemical analysis, a fairly good linear relationship passing through the origin of the coordinates is obtained, which would indicate that $\mathrm{N}$ and $\mathrm{C}$ atoms are not predominantly trapped by them. Thus, once $k$ is determined experimentally, the concentration of the interstitially dissolved $\mathrm{N}$ and $\mathrm{C}$ may be calculated. However, $k$ must be adjusted when the sample has crystal directionality. ${ }^{17), 18)}$ Fig. 1 shows the results for C. ${ }^{19)}$ From this data, $k$ is found to depend upon the purity and the grain size of the steel. This was also confirmed by Lagerberg ${ }^{20)}$ and Stark. ${ }^{21)}$ It is noted that the Snoek peak height decreases with the grain size, but the solubility limits of $\mathrm{C}$ have the same constant value of $0.02 \mathrm{wt}^{\mathrm{O}} \%$. This is most likely due to a friction of the $\mathrm{C}$ atoms dissolved in the specimen at $720^{\circ} \mathrm{C}$ (quenching temperature) being trapped on the grain boundaries during quenching. From Fig. 2 which shows the published results, ${ }^{22), 23)}$ it is known that if the grain size becomes under about $100 \mu, k$ increases rapidly.

Fig. 3 shows the results for N. ${ }^{24)}$ In this case, it should be noted that $\mathrm{N}$ dissolves interstitially much more than $\mathrm{C}$, such that above $0.05 \%$, the precipitation occurs even at room temperature. ${ }^{25)}$ As may be seen in Fig. 4, $k$ depends slightly upon the grain size.

Lagerberg reported that there was no effect of grain size if $\mathrm{N}$ content was below $0.006 \%$. It is of course a problem as to which coefficient should be used for commercial steels, which are always fine-grained and contain alloying elements, but it is presumed that so long as the trapped $\mathrm{N}$ and $\mathrm{C}$ have no effect on the problems considered, $k$ for the pure specimen with a large grain should be used. On the contrary, when $\mathrm{C}$ and $\mathrm{N}$ atoms have any interaction with the boundary and the impurities, a different value of $k$ or in some cases, chemical analyses should be used.

At present, the following formula is used for practical purposes. ${ }^{26)}$

$$
\mathrm{N}, \mathrm{C}(\mathrm{wt} \%)=0.0043 \times \mathcal{T}_{\max .} \times(1 / Q)_{\max } .
$$

\section{Effect of Alloying Elements upon the Snoek Peak}

Sladak and Dijkstra ${ }^{27}$ ) showed that the alloying elements (Mn, Cr, Mo, V) induced an abnormal peak of N. Fast et al. ${ }^{28)}$ interpreted that it was caused by $\mathrm{N}$ atoms trapped by the precipitates. The effects of $\mathrm{Si}^{29)}$ and $\mathrm{Al}^{30)}$ upon the Snoek peak have also been reported.

In $\mathrm{Si}$ steel or in extremely pure iron, the Snoek peak is greatly disturbed by the interaction between the magnetic domain wall and $\mathrm{N}$ and $\mathrm{C}$ atoms. Therefore, measurement must be made under a magnetic field. A weak field will be sufficient to saturation, especially in the experiment of low stress amplitude (Fig. 5). ${ }^{31), 32)}$

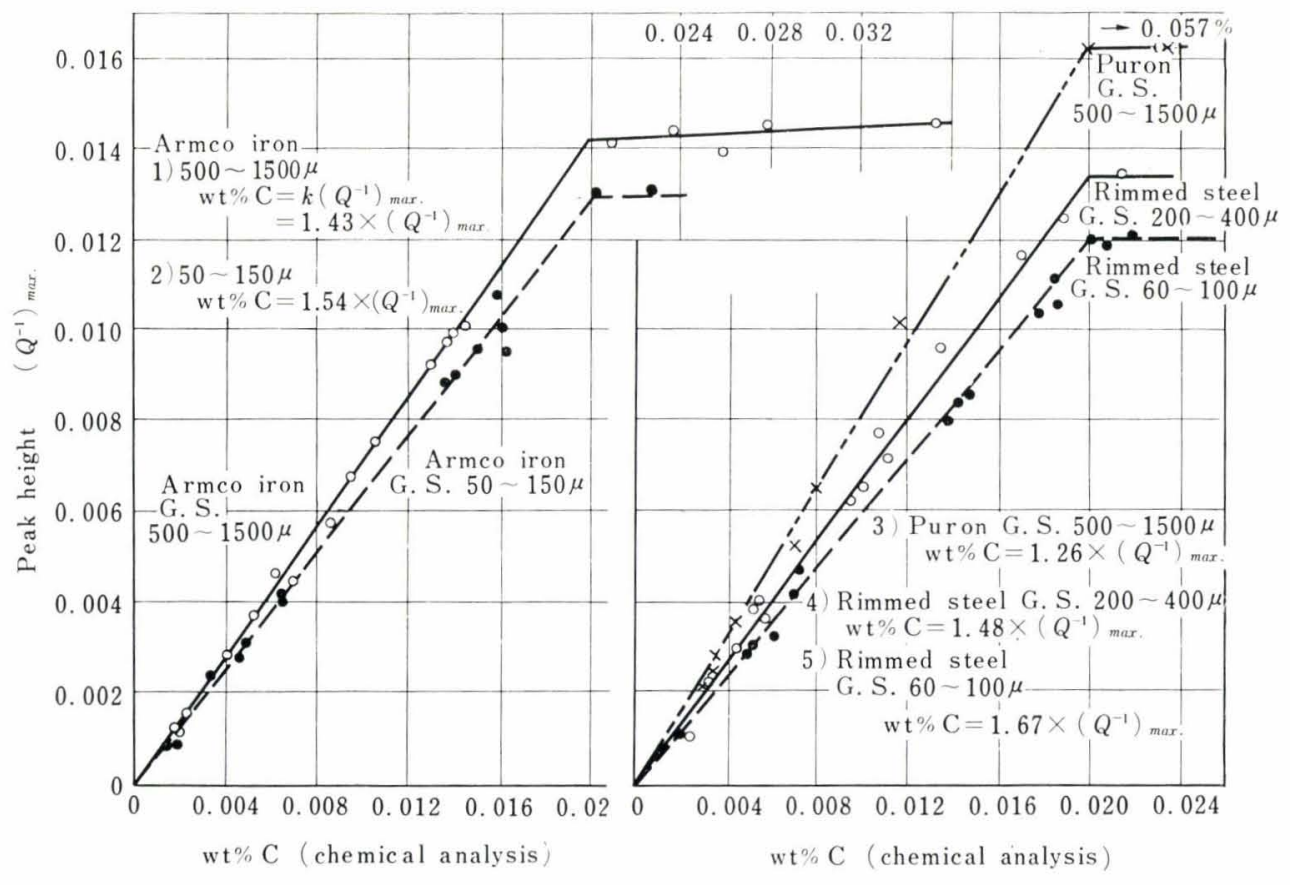

Fig. 1.

Relation between $(1 / Q)_{\max }$. and $\mathrm{C}$ content.

Freq : $600 \mathrm{c} / \mathrm{s}$, puron (G.S. $500-1500 \mu)$, Armco iron (G.S. $50-150 \mu, 500-1500 \mu$ ), rimmed steel (G.S. $60-100 \mu$, $200-400 \mu)$ 


\section{Solubilities of $\mathcal{N}$ and $C$ in Iron and Steel}

Numerous studies have been made to determine solubilities of $\mathrm{N}$ and $\mathrm{C}$ in iron and steel by IF. These are shown in Figs. $6^{33) \sim 35)}$ and $7 .^{21), 36)}$ It can be seen that the solubility of $\mathrm{C}$ is lower than that previously

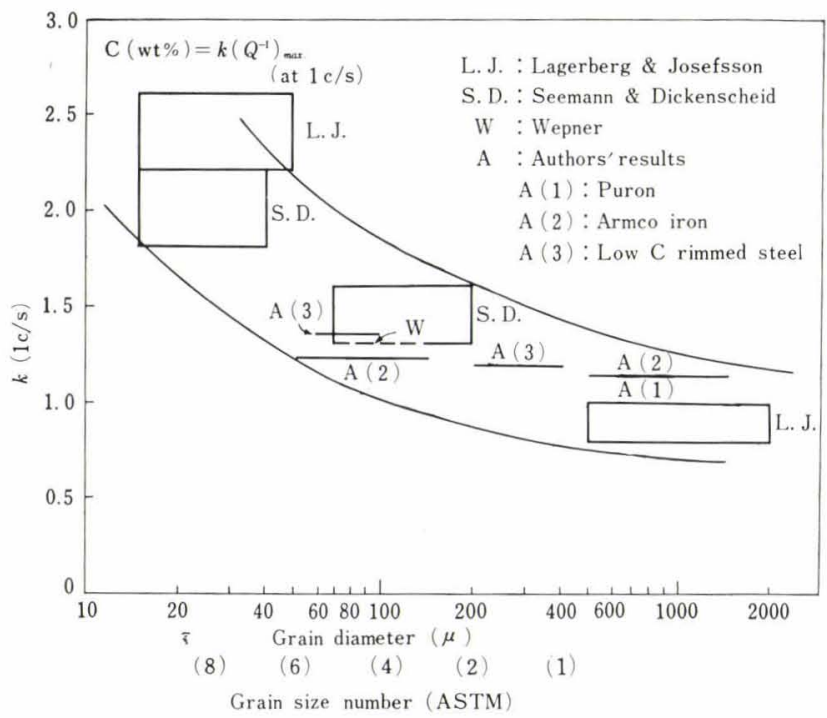

Fig. 2. Influence of grain size on proportionality coefficient between wt \% C of a sample and its Snoek peak height. (coefficient adjusted to $1 \mathrm{c} / \mathrm{s}$ )

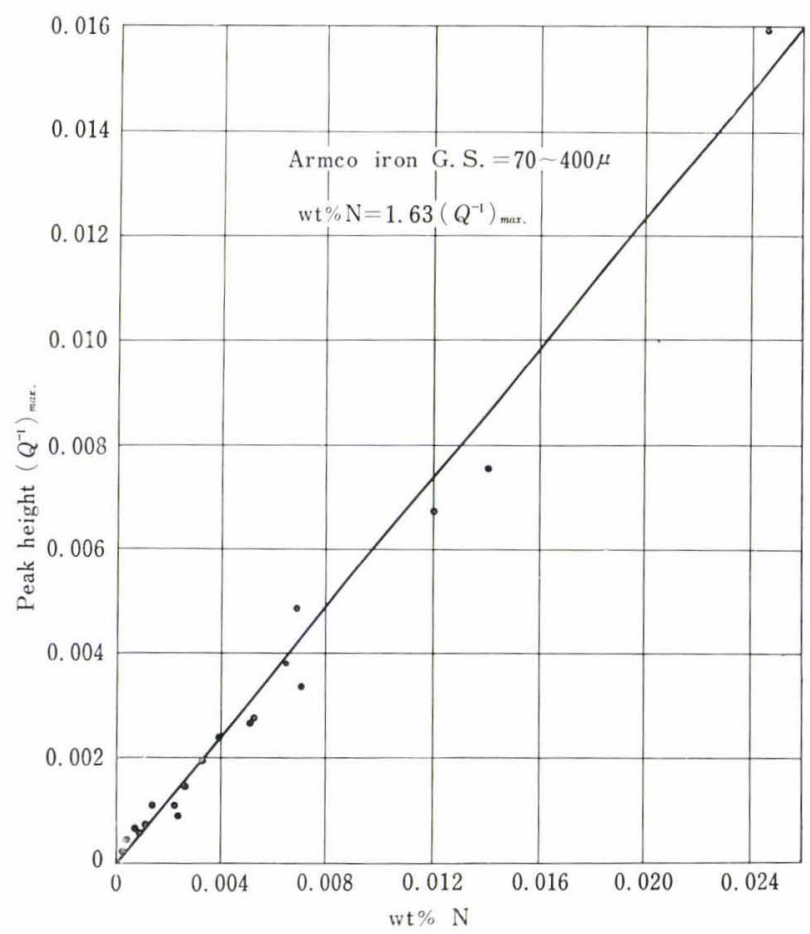

Fig. 3. Relation between $(1 / Q)_{\max }$ and $\mathrm{N}$ content. freq : $600 \mathrm{c} / \mathrm{s}$, Armco iron (G.S. : 100-170 $\mu$ ) determined by microscopic observation or chemical analysis. Some results concerning commercial steels are presented. ${ }^{29), 37)}$ Fig. 8 shows results for Al-killed and rimmed deep drawing steels. ${ }^{38}$ Solubility of $\mathrm{N}$ becomes almost zero between $500^{\circ} \sim 700^{\circ} \mathrm{C}$ in the steel containing $0.05 \%$ sol. $\mathrm{Al}$, and that of $\mathrm{C}$ is also fairly influenced by sol. Al.

Fig. 9 shows another example of $2.5 \% \mathrm{Ni}$ steel, where the as-rolled sample is annealed at each temperature nearly to equilibrium, and then quenched. On $400^{\circ} \mathrm{C}$ annealing, $\mathrm{N}$ peak drops abruptly due to the formation of AlN. By annealing around $700^{\circ} \mathrm{C}$ the $\mathrm{C}$ peak drops abruptly due to the decrease of ferrite caused by martensite transformation.

\section{Relation to Strain Aging}

In rimmed steel sheets, the yield point elongation, which was not observed soon after the skin pass, re-

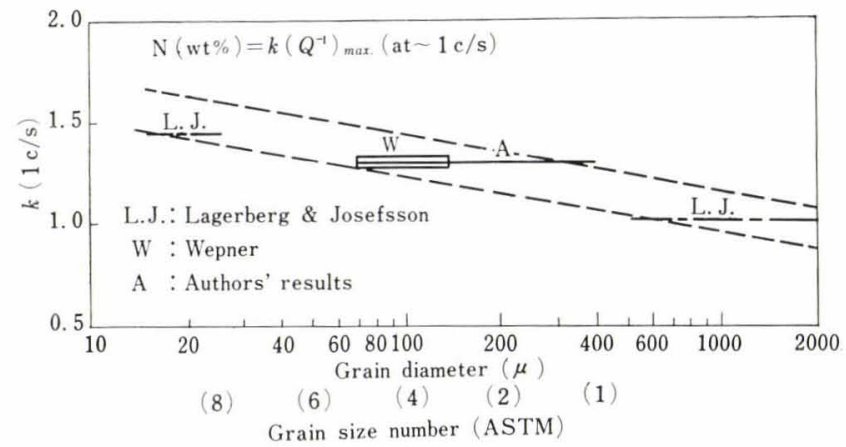

Fig. 4. Influence of grain size on proportionality coefficient between wt \% N of a sample and its Snoek peak height. (coefficient adjusted to $1 \mathrm{c} / \mathrm{s}$ )

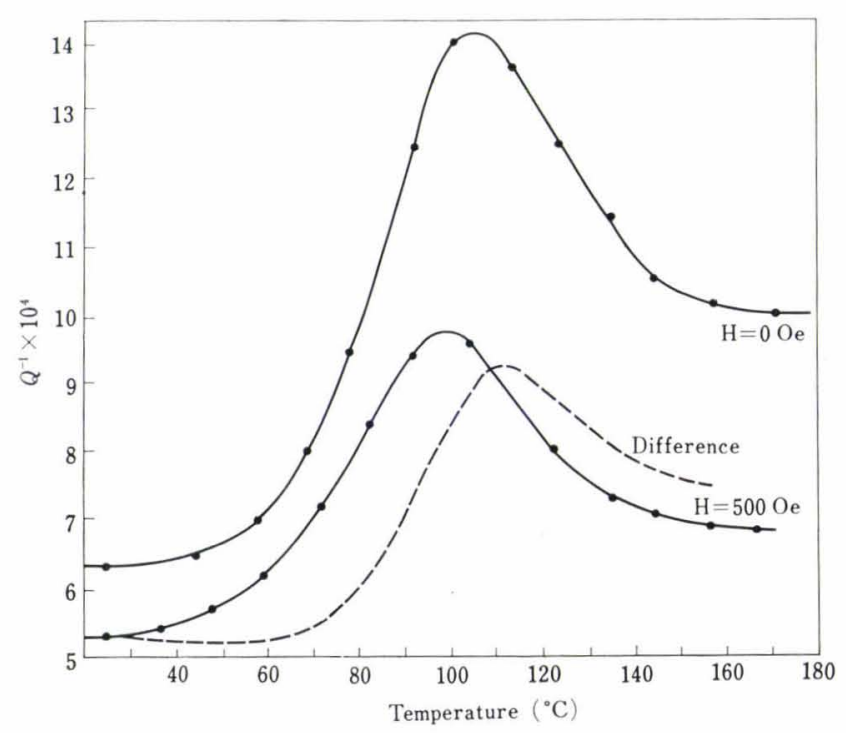

Fig. 5. Effect of magnetic field on the Snoek peak of C. Ferrovac-E (Mimura et al.) 
appears during aging. This is explained by the diffusion of $\mathrm{N}$ and $\mathrm{C}$, and their pinning effects of freed dislocations. Therefore, it is supposed that there is a very close relationship between the strain aging index and the quantity of interstitial $\mathrm{N}$ and $\mathrm{C}$. Fig. 10 shows results of experiments, ${ }^{39)}$ where wet- $\mathrm{H}_{2}$ treated sheets were charged with $\mathrm{N}$ or $\mathrm{C}$, homogenized, quenched, strained $7.5 \%$, and aged at $100^{\circ} \mathrm{C}$ for $1 \mathrm{hr}$. Up to $7 \times 10^{-4} \mathrm{wt}^{\%} \mathrm{~N}$ or $\mathrm{C}$, aging indices are almost pro-

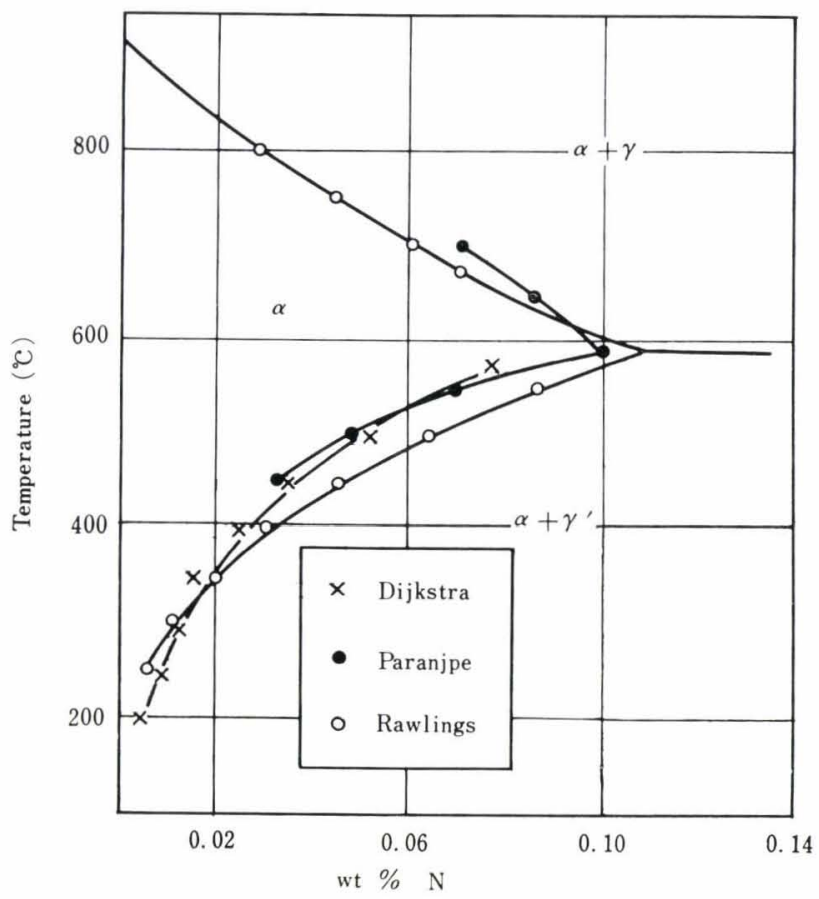

Fig. 6. Solubility of $\mathrm{N}$ in iron determined by IF

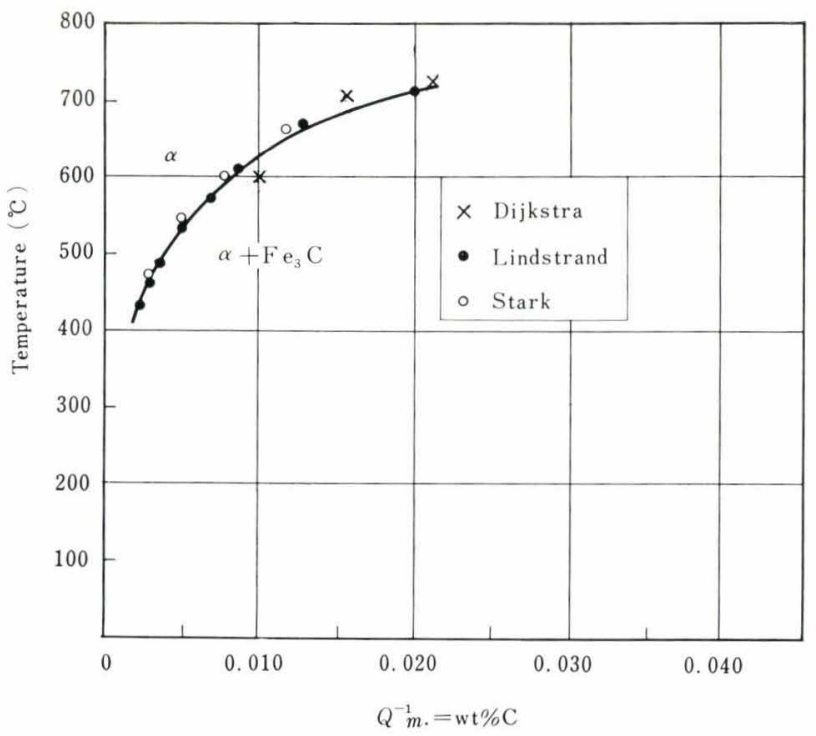

Fig. 7. Solubility of $\mathrm{C}$ in iron determined by $\mathrm{IF}$ portional to the contents of interstitial $\mathrm{N}$ or $\mathrm{C}$, but beyond this quantity, tendency for saturation is observed.

Probably, with small concentration, the Cottrell effect plays the principal role, while with large concentration, precipitation around the dislocations is the cause. It should be noted that iron containing $\mathrm{P}$ shows a much higher saturation value.

\section{Precipitation of $\mathcal{N}$ and $C$}

Up to now, a number of studies have been made on the precipitations. ${ }^{33), 40) \sim 49)}$ If the initial concentration of interstitial atoms is $c_{m}$, and the concentration at the precipitation rate of $W$ is $c$, then

$$
c / c_{m}=1-W
$$

Experimentally, the data can be expressed as

$$
-\ln (1-W)=(t / \tau)^{m}
$$

where $\tau$ and $m$ are constant. According to even the most advanced theories, it is very difficult to decide the characteristics of precipitation from $m$ as formulated by Zener et al.11

As an example of applications, Fig. 11 shows the precipitations of $\mathrm{N}$ and $\mathrm{C}$ in the annealing process of Al-killed deep drawing steel sheets. From the final values, the aging characteristics of the sheets under different cooling conditions can be estimated.

\section{Amplitude Dependence and Köster Effect}

If the amplitude of oscillation is increased, at some amplitude level, IF abruptly increases from the almost

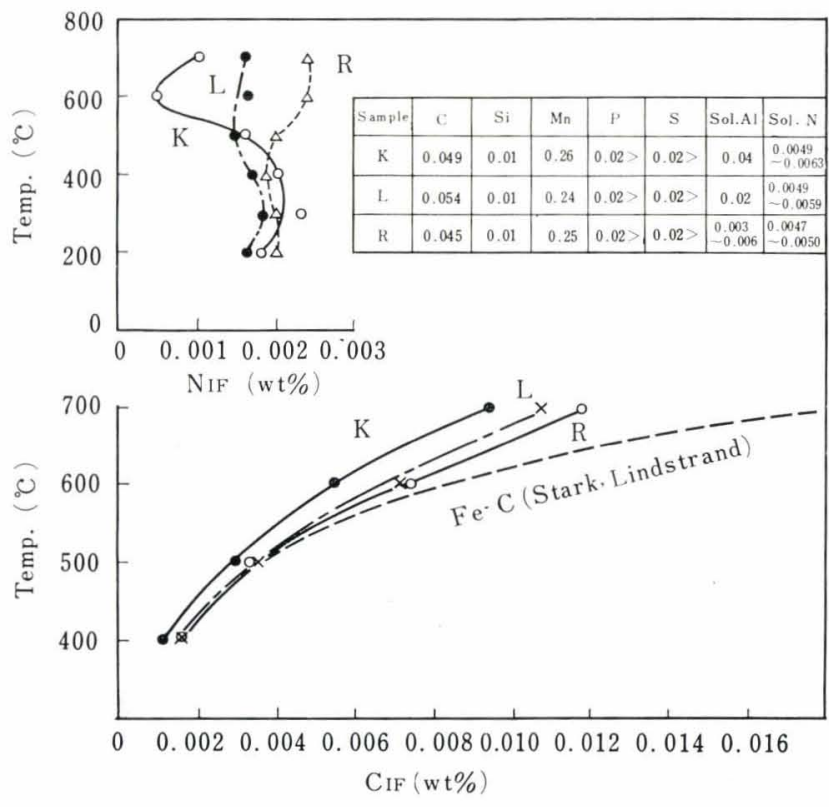

Fig. 8. Solubility-of $\mathrm{C}$ and $\mathrm{N}$ in three Al-killed deep drawing steel sheets measured by IF 
constant value. This fact is called the amplitude dependence of IF. If metals are deformed, IF markedly increases, but decreases very rapidly with time to some definite level. Such phenomenon is also observed when metals are quenched. These effects are all explained by the interactions between dislocation and interstitial atoms, vacancies and precipitates anchoring dislocations.

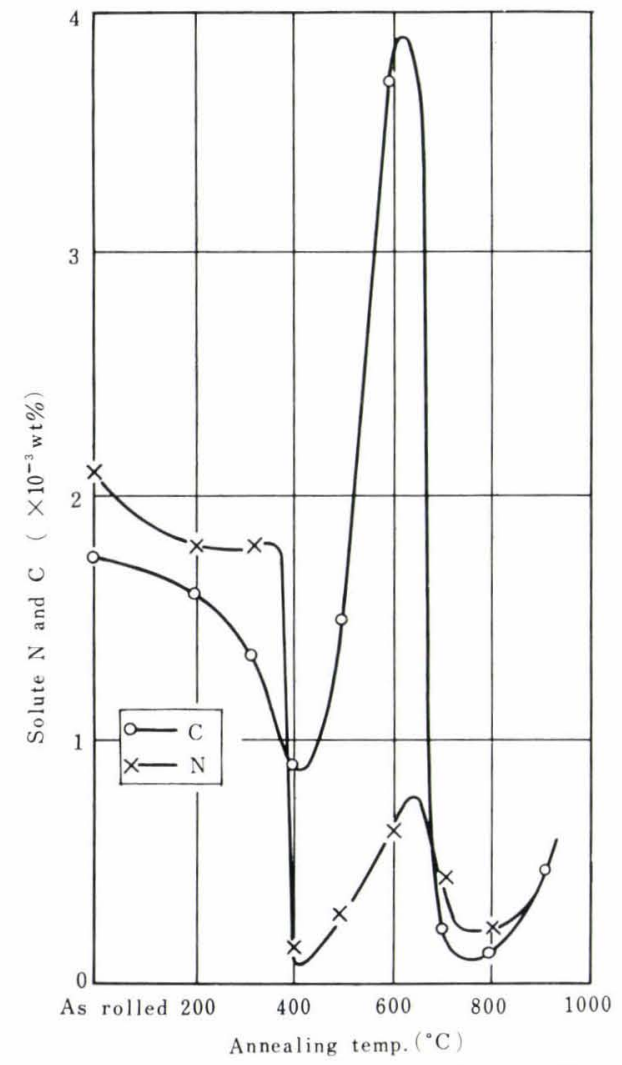

Fig. 9. Solubilities of $\mathrm{N}$ and $\mathrm{C}$ in $2.5 \% \mathrm{Ni}$ steel (C 0.11 , sol. Al $0.026, \mathrm{Ni} 2.38 \%)$. Samples annealed at $200^{\circ} \mathrm{C}$ (100 hours), $315^{\circ} \mathrm{C}(77.5), 400^{\circ} \mathrm{C}(50)$, $500^{\circ} \mathrm{C}(30), 600^{\circ} \mathrm{C}(10), 700^{\circ} \mathrm{C}(4), 800^{\circ} \mathrm{C}(2), 900^{\circ} \mathrm{C}$ (1) and water-quenched

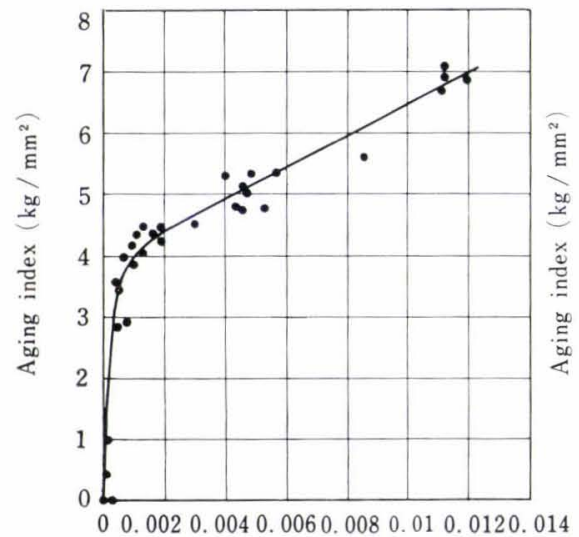

$\mathrm{C} w \mathrm{w} \%$

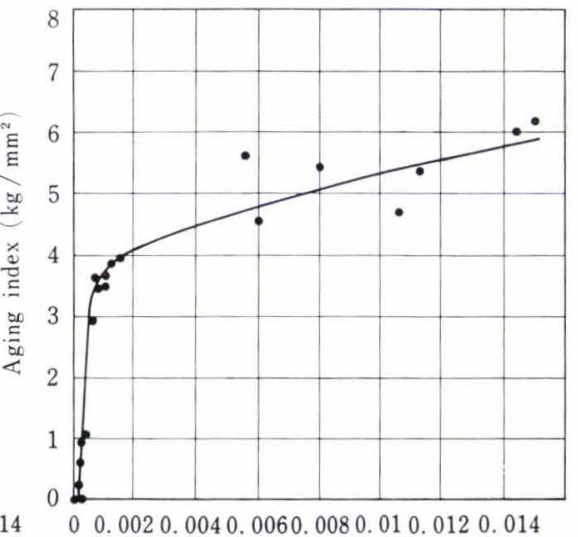

$\mathrm{N} w \mathrm{t} \%$
1. The Theories of IF Caused by the Movement of Dislocations $\left.^{12)}, 50\right), 51$ )

There are two main factors which induce the IF due to the movements of dislocations. One is the resonance of dislocation loops with the alternating stress. From Granato-Lücke's theory, ${ }^{12), 51)}$ the resonance frequency is very high, and in the $\mathrm{KC}-\mathrm{MC}$ range, IF is proportional to the frequency of stress:

where $k_{1}=$ const.,

$$
(1 / Q)_{\mathrm{I}}=k_{1} A L^{4} \omega
$$

$\omega=$ angular frequency,

$\Lambda=$ density of dislocations,

$L=$ mean length of dislocation loop.

In the amplitude independent range, the change of IF with time is explained by the change of loop length.

The other mechanism is caused by the movement of dislocation loops with hysteresis. From GranatoLücke's theory, this IF is expressed as

where $k_{2}, k_{3}=$ const.,

$$
(1 / Q)_{\mathrm{H}}=\frac{k_{2} A L_{\mathrm{n}}^{3}}{L_{\mathrm{c}}^{2} \varepsilon_{0}} \exp \left(-\frac{k_{3}}{L_{\mathrm{c}} \varepsilon_{0}}\right)
$$

$$
\begin{aligned}
\varepsilon_{0}= & \text { maximum strain amplitude, } \\
L_{\mathrm{c}}= & \text { mean length of dislocation loop } \\
& \text { formed by impurity atoms, } \\
L_{\mathrm{n}}= & \text { mean length of dislocation loop } \\
& \text { formed by dislocation network. }
\end{aligned}
$$

This part of IF is, in its nature, static, and thus frequency independent, and strongly amplitude dependent. Whereas, IF caused by resonance of dislocation loop is frequency dependent and amplitude independent.

\section{Some Experimental Results for Amplitude Dependence}

Fig. 12 is the results showing the amplitude dependency in Puron and Puron purified by zone melting. ${ }^{52)}$ Presumably, as the result of purification, the dislocation density is decreased, so that it could be said that the density of impurities on dislocations becomes very low. Besides, a remarkable difference can be seen between
Fig. 10.

Relation between strain-aging indices and interstitial $\mathrm{N}$ and $\mathrm{C}(\mathrm{C} 0 \sim 0.012, \mathrm{~N} 0 \sim$ 0.014 , Si 0.001 , Mn 0.24 , sol. Al 0.002 wt $\%$ ) 

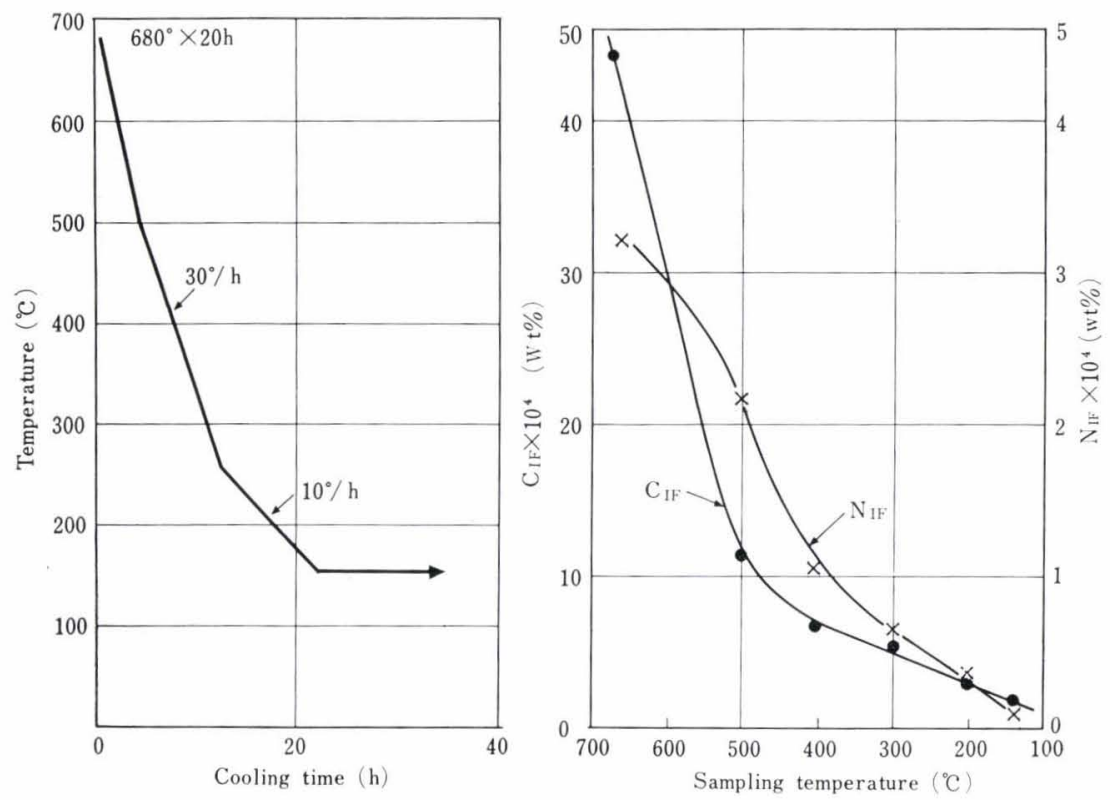

Fig. 11.

Change in quantity of interstitial $\mathrm{N}$ and $\mathrm{C}$ during annealing process.

(C 0.048 , Si 0.01 , Mn 0.33 , sol. Al $0.046 \%$ )

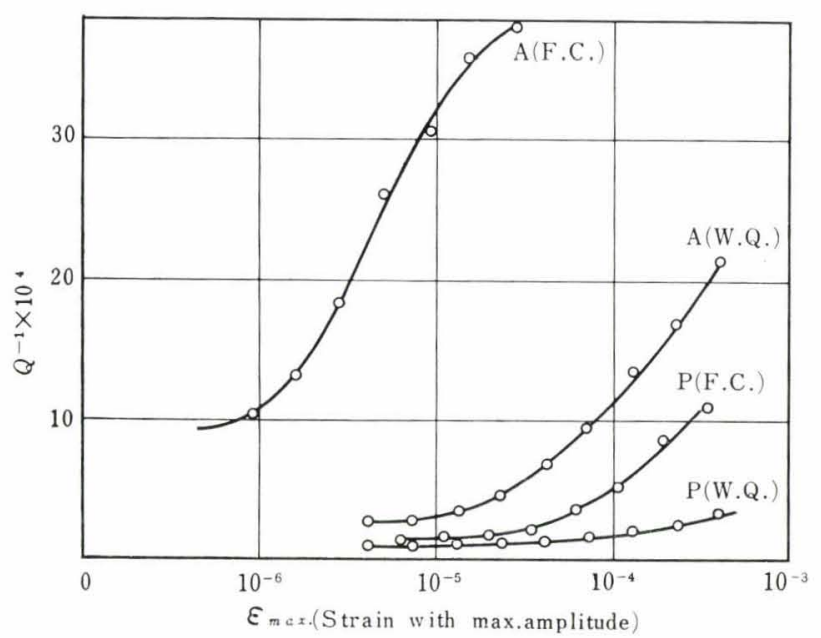

Fig. 12. Amplitude dependency in Puron and zonerefined Puron which are water-quenched or furnace-cooled after $600^{\circ} \mathrm{C} \times 40 \mathrm{hr}$ annealing

water-quenched and furnace-cooled specimens, which is most distinct with specimens of zone refined Puron. It is thought that in quenched specimens there are more vacancies and local strains to disturb dislocation movement. To explain correctly the results of Fig. 12, however, the magnetic effect must also be considered.

Fig. 13 shows the amplitude dependence of IF of deformed Al-killed deep drawing steel sheets. ${ }^{53)}$ The annealed sheet shows very great dependence, which decreases with degree of deformation. Amplitude independent IF increases with degree of deformation. This is explained by the rapid augumentation of density of dislocations rather than by the diminution of loop length.

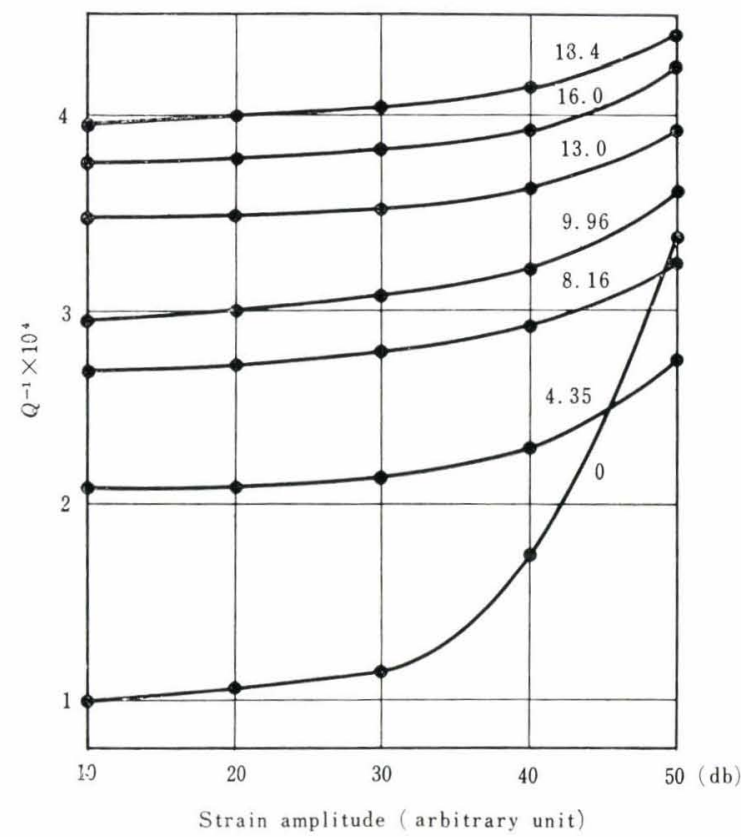

Fig. 13. Strain-amplitude dependence of IF in Al-killed deep drawing steel sheet. Figures on the curves represent the degree of cold-work (\%, about $610 \mathrm{c} / \mathrm{s})$

\section{Köster Effect after Quenching}

In Figs. 14 and 15 are shown the changes of IF of two samples after quenching, - wet- $\mathrm{H}_{2}$ treated Armco iron, and wet- $\mathrm{H}_{2}$ treated, $\mathrm{N}_{2}$ charged Armco iron. The former shows very little decrease of IF with time, but the latter shows a great change. Comparing these two results, it can be said that vacancies have 


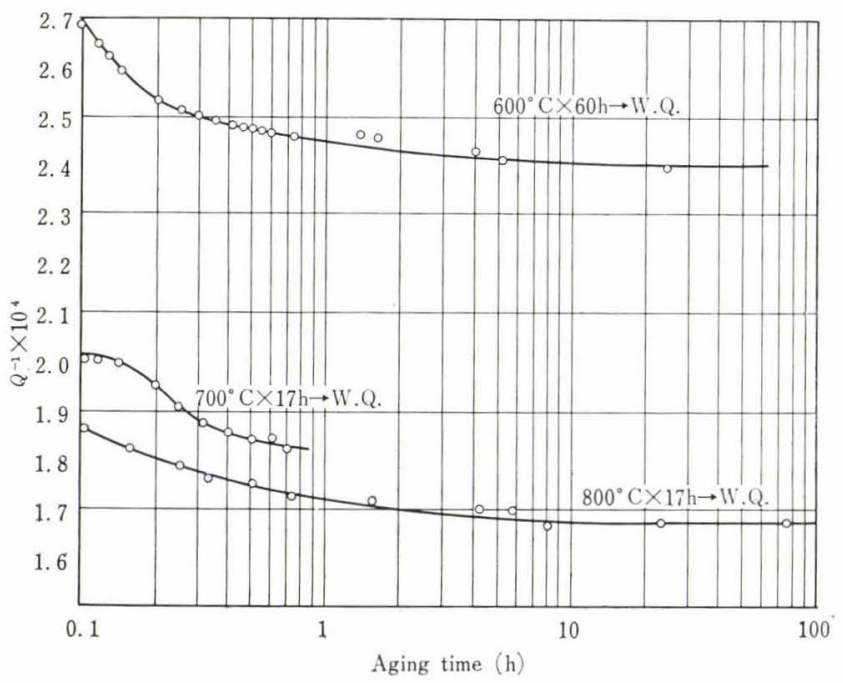

Fig. 14. Köster effect of wet- $\mathrm{H}_{2}$ treated Armco iron after water-quenching (room temp.)

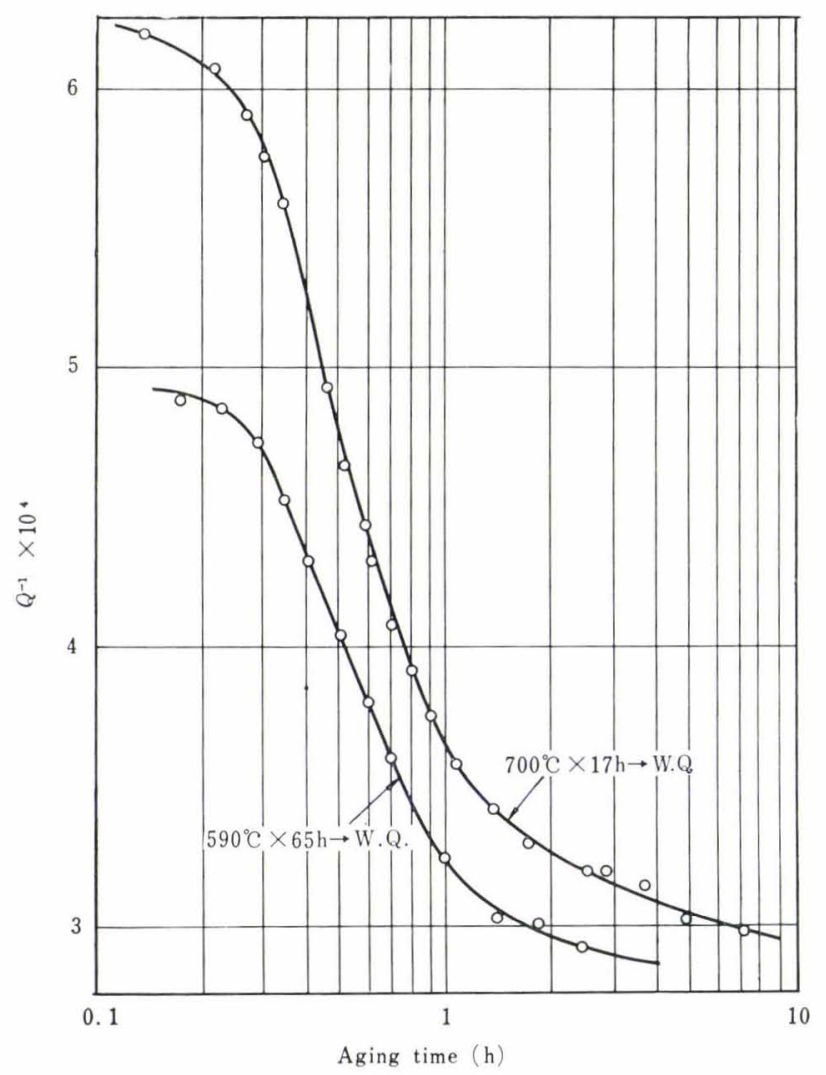

Fig. 15. Köster effect of wet- $\mathrm{H}_{2}$ treated and $\mathrm{N}_{2}$ charged Armco iron after water-quenching (room temp.)

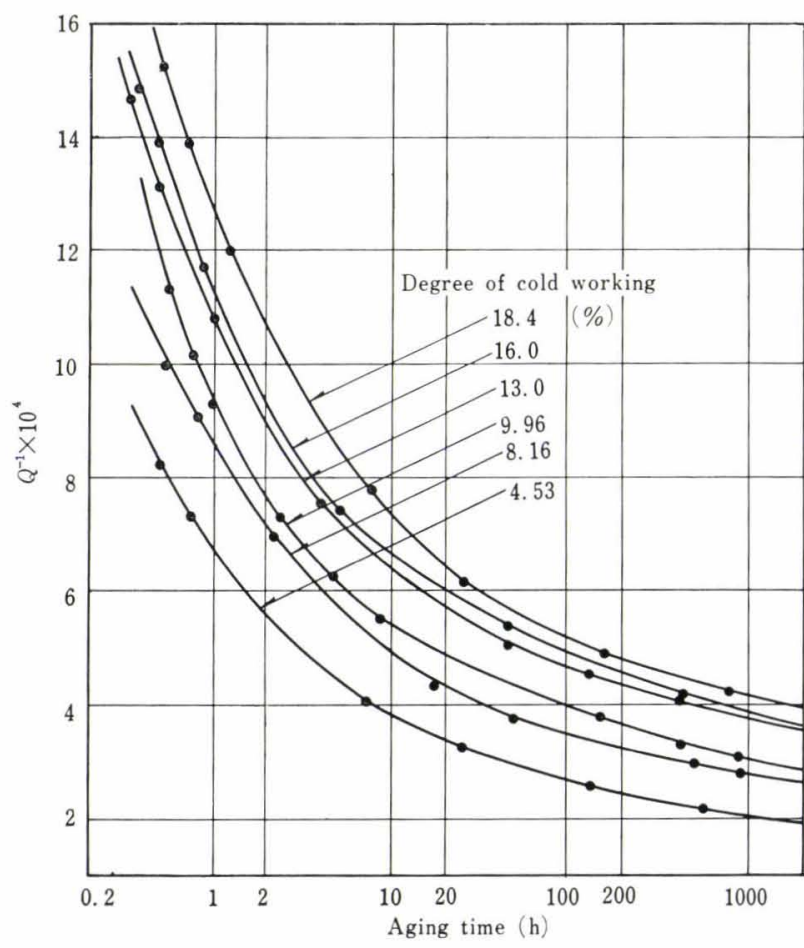

Fig. 16. Change of amplitude independent IF of Alkilled deep drawing steel sheet after cold work $\left(27^{\circ} \mathrm{C}, 610 \mathrm{c} / \mathrm{s}\right)$. (C 0.055 , Si 0.019 , Mn 0.32, sol. Al 0.06 , sol. N $0.0062 \%$ )

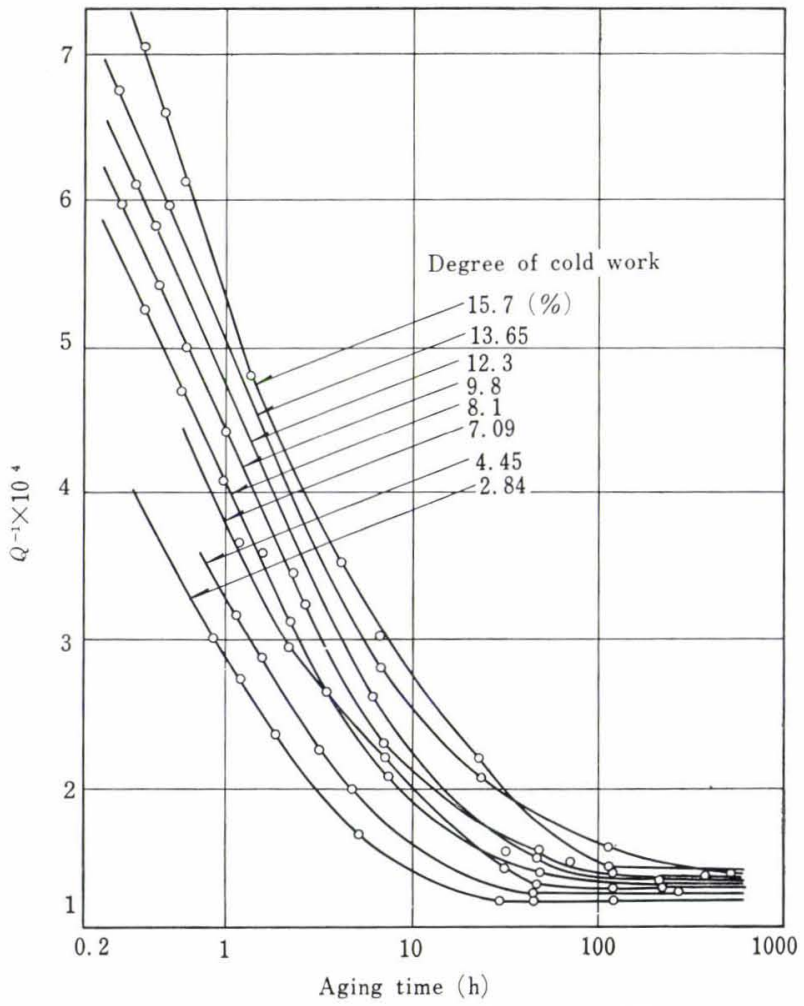

Fig. 17. Change of amplitude independent IF of pure iron after cold work $\left(18^{\circ} \mathrm{C}, 580 \mathrm{c} / \mathrm{s}\right)$. (C 0.016 , Si 0.014 , Mn 0.03 , sol. N 0.0048 ) 
less effect than inter stitial atoms. Beaulieu et al. ${ }^{54}$ measured changes of IF of quenched steels and showed that IF was amplitude independent between $10^{-4} \sim$ $10^{-6}$ strain range, and frequency dependent.

\section{Köster Effect after Deformation}

In Figs. 16 and 17 are shown the changes of IF with time after cold work, at room temperature, ${ }^{55)}$ of Al-killed steel and commercial pure iron. The interstitial atoms $(\mathrm{N}+\mathrm{C})$ measured by $\mathrm{IF}$ are $1.6 \times 10^{-5} \mathrm{wt} \%$ for killed steel, $2.5 \times 10^{-4} \mathrm{wt}^{\mathrm{O}} \%$ for pure iron. Killed steel shows a great increase of IF just after deformation, and its recovery takes place very slowly and can be observed even after $1500 \mathrm{hr}$. On the contrary, in pure iron, the increase is not so large, and recovery is completed after only $200 \mathrm{hr}$.

These phenomena would be explained by equation

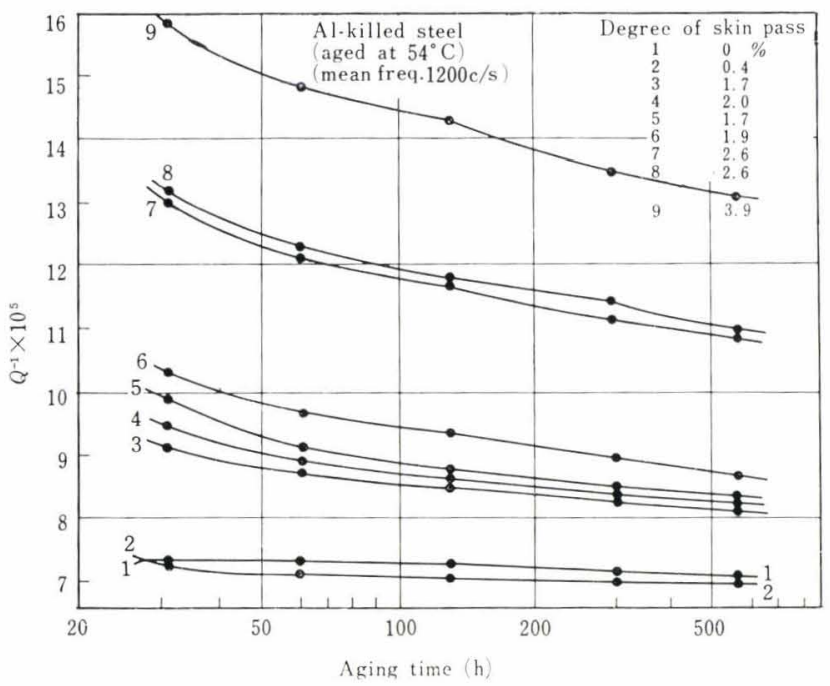

Fig. 18. Köster effect of skin passed Al-killed deep drawing steel sheet $\left(54^{\circ} \mathrm{C}, 1200 \mathrm{c} / \mathrm{s}\right)$.

(C 0.058, Si 0.013, Mn 0.36, sol. N 0.0075, sol. Al 0.048$)$
(7), but when interstitial atoms are small in number, vacancies also play an important role in the first stage of recovery.

Figs. 18 and 19 show the changes of IF after skin pass observed in Al-killed, and rimmed steels. In killed steel after $800 \mathrm{hr}$ at $54^{\circ} \mathrm{C}$, IF continues to decrease and it is inferred that the effect of skin pass has not disappeared. On the other hand, in rimmed steel, after $50 \mathrm{hr}$, recovery is already completed, and the fresh dislocations are anchored by interstitial atoms with a shorter loop length. In Fig. 20 is shown the relationship between the degree of skin pass and IF after $100 \mathrm{hr}$ aging at $54^{\circ} \mathrm{C}$. In rimmed steel, IF is decreased with the degree of skin pass, but in killed steel, skin pass always increases IF. This fact can be explained by the large difference in the quantity of interstitial $\mathrm{N}$ and $\mathrm{C}$.

\section{Conclusions}

Although in a very limited field, some examples of

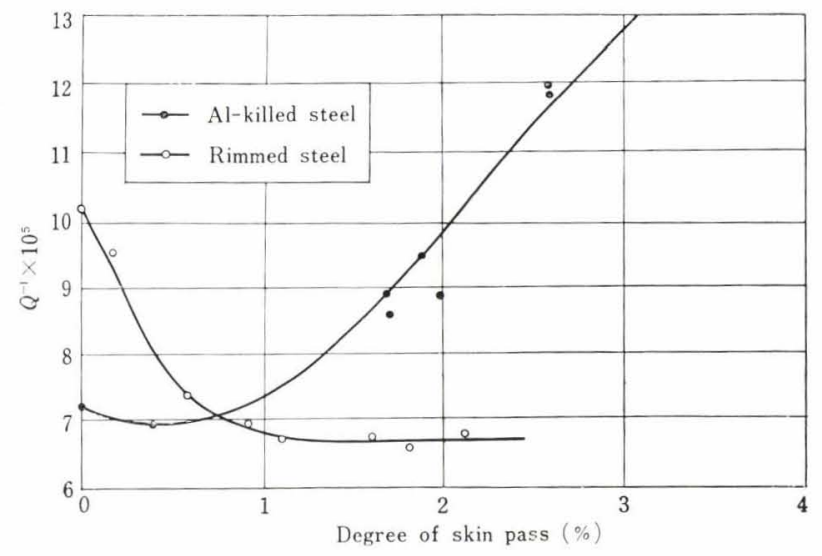

Fig. 20. Relation between the degree of skin pass and IF after $100 \mathrm{hr}$ aging at $54^{\circ} \mathrm{C}$

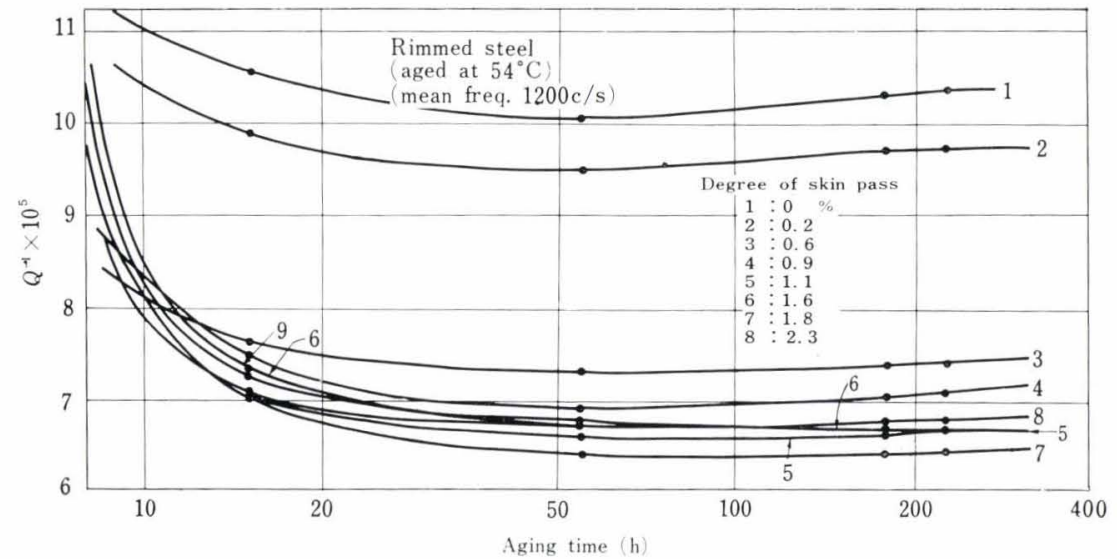

Fig. 19.

The Köster effect of skin passed rimmed steel $\left(54^{\circ} \mathrm{C}, 1200 \mathrm{c} / \mathrm{s}\right)$.

(C 0.064 , Si 0.008 , Mn 0.40, sol. N 0.0010 , sol. Al 0.002) 
applications of IF were presented. It is believed that there are many phenomena about IF that are unknown or unexplained, but nevertheless, the measurement of IF should be useful for practical problems. It would be the authors' great pleasure, if this short introduction may be of use, even in a little degree, to the researches in this field.

\section{REFERENCES}

1) C. Zener: Elasticity and Anelasticity of Metals, (1948).

2) A. S. Nowick: Progress in Metal Physics, 4 (1953).

3) D. H. Nilbett and J. Wilks: Advances in Physics, 9 (1960).

4) P. M. Robinson and R. Rawlings: Iron and Steel, 3 (1958), $65,97$.

5) J. L. Snoek: Physica, 6 (1939), 591.

6) J. L. Snoek : ibid., 8 (1941), 711.

7) D. Polder: Philips Res. Rep., 1 (1945), 1.

8) W. R. Thomas and G. M. Leak: Phil. Mag., 45 (1954), $656,986$.

9) C. A. Wert and C. Zener: Phys. Rev., 76 (1949), 1169.

10) C. A. Wert: ibid., 79 (1950), 601.

11) A. S. Nowick: ibid., 80 (1950), $249 ;$ J. Appl. Phys., 25 (1954), 1129.

12) A. Granato and K. Lücke: ibid., 27 (1956), 583, 789.

13) W. Köster: Z. Metallk., 32 (1940), 282.

14) T. S. Ke, P. T. Yung and Y. N. Wang: Acta Physica Sinica, 11 (1955), 91 ; Scientia Sinica, 4, 263.

15) T. S. Ke: Trans. Met. Soc. Amer. Inst. Min., Met. \& Pet. Eng., 176 (1948), 448.

16) T. S. Ke: J. Appl. Phys., 20 (1947), 274.

17) G. Lagerberg and A. Josefsson: Acta Met., 7 (1959), 137.

18) R. Rawlings: ibid., 4 (1956), 213.

19) K. Aoki et al.: J. Japan Inst. Met., 1 (1962), 49.

20) G. Lagerberg and A. Josefsson: Acta. Met., 3 (1955), 236.

21) P. Stark, B. L. Averbach and M. Cohen: ibid., 6 (1958), 149.

22) W. Wepner: Arch. Eisenhüttenw., 27 (1956), 55.

23) H. J. Seemann and W. Dickenscheid: Acta. Met., 6 (1958), 62.

24) K. Aoki et al: J. Japan Inst. Met., 26 (1962), 50.

25) W. Wepner: Arch. Eisenhüttenw., 27 (1956), 449.

26) K. Aoki et al.: J. Japan Inst. Met., 26 (1962), 51.
27) L. J. Dijkstra and R. J. Slad: Trans. Met. Soc., Amer. Inst. Min., Met. \& Pet. Eng., 197 (1953), 69.

28) J. D. Fast and J. L. Meijering: Philips Res. Rep., 6 (1953), 1.

29 D. A. Leak, W. A. Thomas and G. M. Leak: Acta Met., 3 (1955), 501.

30) F. H. Laxar, J. W. Faame and D. J. Blickwede: Trans. Amer. Soc. Metals, 53 (1961), 683.

31) R. E. Mariger, E. B. Swetnam, L. L. Marsh and G. K. Manning: NACA, TN (1958) 4328.

32) H. Mimura et al.: Rep. Tokyo Res. Inst., Yawata Iron \& Steel Co., Ltd.

33) L. J. Dijkstra: Trans. Met. Soc., Amer. Inst. Min., Met. \& Pet. Eng., 185 (1949), 252.

34) V. G. Paranjpe et al. : ibid., 188 (1950), 261.

35) R. Rawlings and D. Tambini : J. Iron \& Steel Inst. (U. K.), 189 (1956), 302.

36) E. Lindstrand: Acta Met., 3 (1955), 431.

37) S. N. Polyakov and K. F. Starodubov: Fiz. Metal Metalloved, 6 (1958), 1110.

38) K. Aoki et al.: J. Japan Inst. Met., 26 (1962), 437.

39) S. Sekino et al.: Preprint, 51st Meeting, Japan Inst. Met.

40) R. H. Dorremus: Act. Met., 5 (1957), 392.

41) C. Wert: J. Appl. Phys, 20 (1949), 943.

42) C. Zener: ibid., 20 (1949), 950.

43) S. Harper: Phys. Rev., 83 (1951), 709.

44) F. Ham: J. Appl. Phys., 30 (1959), 915.

45) W. Wepner: Acta. Met., 5 (1957), 703.

46) R. H. Doremus: ibid., 6 (1958), 674.

47) A. Josefsson and E. Kula: Trans. Met. Soc. Amer. Inst. Min., Met. \& Pet. Eng., 194 (1952), 161.

48) W. Köster and L. Bangert: Arch. Eisenhü̈tenw., 25 (1954), 231.

49) W. Pitsch and K. Lücke: ibid., 27 (1956), 45.

50) J. S. Köhler: The Influence of Dislocations and Impurities on the Damping and the Elastic Constant of Metal Single Crystals, (Imperfections in Nearly Perfect Crystalls, 1952).

51) K. Lücke and A. Granato: Internal Friction due to Dislocation, (Dislocation and Mechanical Properties of Crystals, 1957).

52) H. Mimura et al.: Rep. Tokyo Res. Inst., Yawata Iron \& Steel Co., Ltd.

53) K. Aoki et al.: J. Japan Inst. Met., 23 (1959), 696.

54) C. E. Beaulieu, A. Dube and G. Letender: Trans. Met. Soc. Amer. Inst. Min., Met. \&O Pet. Eng., (1960), 558.

55) K. Aoki et al.: J. Japan Inst. Met., 24 (1960), 246. 